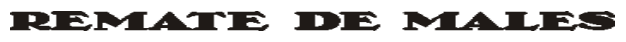

Campinas-SP, v.41, n.2, pp. 569-595, jul./dez. 2021

\title{
OS ENSAIOS LONGOS DO POETA-CRÍtítCo MÁrio FAUSTINo
}

\author{
The Poet-Critic Mario Faustino's \\ LONG ESSAYS
}

\author{
João Moura Fernandes ${ }^{1}$ \\ Braulio Fernandes ${ }^{2}$
}

\begin{abstract}
Resumo: O poeta-crítico Mário Faustino (1930-1962) - vitimado por um acidente de avião aos trinta e dois anos de idade, no auge da sua produção - raramente é ignorado pelos estudiosos da poesia brasileira dos anos 1950 e da sua crítica. Os poemas do autor e as discussões por ele levantadas na sua página "Poesia-Experiência" (publicada semanalmente no Suplemento Dominical do Jornal do Brasil entre 1956 e 1958) tornaram-se, de fato, tópicos incontornáveis para compreender os debates literários daquele momento. Neste artigo, o que se pretende é apresentar a trajetória crítico-criativa de Faustino para, assim, situar e abordar mais detidamente a parte da obra do autor que merece mais atenção: a dos ensaios longos, de caráter instrumental e didático, notadamente a daqueles compostos como "Diálogos de oficina". Empreendemos a nossa investigação em seis breves etapas: na primeira, apresentamos um panorama da carreira do autor, destacando os desafios estéticos que ele buscou superar; na segunda, o modo como se organizou a sua obra, tendo em vista situar os três ensaios/diálogos de oficina eleitos para discussão nas etapas seguintes; na terceira, o modo como a última parte dessa obra se baseou em uma determinada poética de fragmentos; na quarta, o pensamento do autor sobre a relação poesia-sociedade, base do ensaio "Para que poesia?"; na quinta, as teses de Faustino sobre as relações poeta-mundo e poesia-objetos, bases dos ensaios "O poeta e seu mundo" e “Que é poesia?", respectivamente; na sexta, enfim, tecemos uma síntese da nossa discussão
\end{abstract}

\footnotetext{
${ }^{1}$ Doutorando em Teoria da Literatura e Literatura Comparada pelo Programa de PósGraduação em Letras da Universidade do Estado do Rio de Janeiro (UERJ): <jpmaf96@ gmail.com>.

${ }^{2}$ Professor adjunto do Colégio Pedro II e doutorando em Teoria da Literatura e Literatura Comparada pelo Programa de Pós-Graduação em Letras da Letras da Universidade do Estado do Rio de Janeiro (UERJ): <vialinguagem@gmail.com>.
} 
acerca da posição assumida pelo poeta-crítico, nos seus ensaios, em relação ao sistema poético brasileiro.

Palavras-chave: Mario Faustino; poesia brasileira; crítica de poesia.

Abstract: The poet-critic Mário Faustino (1930-1962), victim of an airplane accident at the age of thirty-two, at the height of his production, is rarely ignored by scholars of the 1950 B Brazilian poetry and literary critics. The poems he published and the discussions he engaged on his weekly page in the newspaper Jornal do Brasil, entitled "Poesia-Experiência" (1956-1958), became unavoidable topics of the literary debates of that period. This article aims to present some of Faustino's critical-creative career facts, in order to contextualize and address one part of the author's works that deserves more attention: the part of the long essays, especially those called "Diálogos de oficina." We undertook our investigation in six brief stages: in the first, we present an overview of the author's career, highlighting the aesthetic challenges he sought to overcome; in the second, the way in which Faustino's works were developed, in order to elucidate the strategic position of the three essays/manufactory dialogues chosen for discussion in the next stages; in the third, the way in which his final writings were based on a specific proposition of a poetics of fragments; in the fourth, the author's thoughts on the poetry-society relationship that are the basis of the essay "Poetry for what?"; in the fifth, Faustino's proposals on the poet-world and poetry-objects relations that are notable on the essays "The poet and his world" and "What is poetry?"; finally, we summarize our arguments about the position taken by the poet-critic Faustino in relation to the Brazilian poetic system.

Keywords: Mário Faustino; Brazilian Poetry; Poetry Criticism.

\section{A ABORDAGEM DE UM PROJETO INTERROMPIDO}

Todo pesquisador de literatura, em algum momento da sua trajetória, precisa lidar com a crítica de um projeto inacabado. São muitos os livros cujo valor estético e/ou filosófico justifica o estudo, mas cuja formulação final foi estabelecida por algum editor, e não contou com o consentimento do autor - afinal, não sendo possível antever a data da própria morte, é natural que se deixe pelo menos o último trabalho, aquele iniciado mais tarde na vida, em aberto. Esse é o caso, por exemplo, de O processo, de Franz Kafka, e de Alabardas, alabardas, de José Saramago, ambos romances de ficção; da imensa arca de Fernando Pessoa, cujos manuscritos foram organizados postumamente em livros e separados de acordo com os seus respectivos heterônimos por pesquisadores dedicados; de quase toda a poesia de Emily Dickinson, descoberta, editada, redescoberta e reeditada após sua morte; dos fragmentos poéticos e dos ensaios críticos de Mário Faustino.

A abordagem de projetos e obras dessa estirpe é especialmente delicada, uma vez que ela exige, por um lado, uma postura condescendente e, por outro, o mesmo rigor analítico do trabalho crítico tradicional. A postura condescendente seria exigida na medida em que não se pode 
atestar o equívoco de projetos cujos fins e princípios ainda se desenhavam quando interrompidos - sobretudo porque, tacitamente, usamos supor que um autor, tivesse a chance, aperfeiçoaria a sua criação e a formularia do modo mais coerente. Por outro lado, apesar de todo o potencial para sempre reprimido, de todo o lamento pela obra que não pôde vir a ser, não se deve abrir mão do rigor que rege a abordagem crítica-investigativa, pois um legado inacabado constitui, ainda assim, um legado, e deve ser encarado em sua formulação definitiva, concreta, aquela que chega até nós.

O tema principal deste trabalho exige tais ponderações iniciais por se tratar dos escritos de um autor que faleceu no auge da sua produção, aos trinta e dois anos de idade. Mário Faustino (Teresina, 22 de outubro de 1930 - Lima, 27 de novembro de 1962) foi um poeta-crítico que tratou com tanta seriedade e erudição os assuntos ligados à arte que se tornou impossível ignorar o impacto que as suas obras, se levadas a cabo na integridade da sua intenção, poderiam realizar no nosso cenário cultural. Se observada a grande repercussão, entre os poetas da sua geração, daquela crítica curta e esparsa que vinha publicando desde 1956 no Suplemento Dominical do Jornal do Brasil (SDJB), nos editoriais do mesmo jornal e nas diversas revistas de arte com as quais contribuía - tendo o autor instaurado, na opinião de Assis Brasil (1973, p. 17), "o espaço onde foram travados os principais debates sobre o concretismo" -, é natural supor que um esforço crítico mais sistemático e ambicioso por parte do mesmo autor, com o alcance de um livro completo em vez de pequenas colunas e páginas jornalísticas, teria ainda maior influência eainda maiores desdobramentos na crítica e na criação da sua geração e das gerações posteriores.

Neste trabalho, optamos por revisitar justamente os ensaios críticos mais longos de Faustino, ensaios que compõem a parte menos lida e comentada da sua obra. Para tanto, selecionamos os três "Diálogos de oficina”, reunidos pela primeira vez em livro logo após o acidente de avião que vitimou o poeta. "Para que poesia?", "O poeta e seu mundo" e "Que é poesia?” compõem a Coletânea 2 (FAUSTINO, 1964), organizada por Assis Brasil, a quem devemos o caráter de projeto unitário independente que eles adquiriram na edição. ${ }^{3}$

\footnotetext{
3 Os três textos foram republicados, posteriormente, como os primeiros capítulos do livro Poesia-experiência (1976) - não mais como um projeto didático-ensaístico independente, mas como registros pontuais do projeto Po-Ex. Nossa hipótese é a de que o protagonismo dos textos centrais e finais do livro de 1976, atrelado à ênfase dada a ele pelos estudiosos de Faustino, colabora para a pouca atenção que os diálogos de oficina recebem.
} 
Empreendemos a nossa abordagem à trajetória de Faustino e aos três ensaios selecionados em seis breves etapas: na primeira, apresentamos de forma panorâmica a carreira do autor e os desafios estéticos que ele buscava superar; na segunda, tendo em vista situar os ensaios em questão, expomos a forma como se desenvolveu sua obra; na terceira, o modo como o autor concebeu a estética de fragmentos em que consistiu a parte final da sua obra; na quarta, o pensamento do autor sobre a relação poesia-sociedade, que baseia o primeiro ensaio da Coletânea 2; na quinta, as teses sobre as relações poeta-mundo e poesia-objetos que embasam o segundo e o terceiro ensaios da mesma Coletânea; por fim, fazemos uma breve conclusão da nossa discussão acerca da posição assumida pelo poeta-crítico Faustino, nos seus ensaios, em relação ao sistema poético brasileiro.

\section{MÁRIO FAUSTINO: CARREIRA E DESAFIOS CRÍTICO- -CRIATIVOS}

Escritor e impresario ${ }^{4}$ da literatura com sólida atuação no terreno da poesia; jornalista, tradutor, crítico literário e poeta; verdadeiro introdutor e divulgador de poéticas modernas de várias partes do mundo no Brasil (por meio, principalmente, da página que concebeu e manteve por dois anos no SDJB, a "Poesia-Experiência"), 5 Faustino desempenhou um intenso e, podemos dizer, extenso trabalho crítico que cobriu um vasto perímetro de temas. Sua preocupação básica e insistente, ao longo dos seus anos

\footnotetext{
${ }^{4} \mathrm{O}$ termo impresario, usado por Faustino para denominar-se a si mesmo, era empregado por Ezra Pound para designar a classe dos poetas que militavam e influenciavam no debate das suas culturas, de modo a distingui-los daqueles que apenas divulgavam seus escritos. ${ }^{5}$ A página esteve em vigor de 23/09/1956 a 1/11/1958. Era dividida em seções: "Poeta Novo" (divulgação de poemas de autores jovens - para ele, a mais importante de todas); "O Melhor em Português" (publicação de poetas portugueses importantes ainda desconhecidos no Brasil); "É Preciso Conhecer" (divulgação de poetas modernos estrangeiros através de traduções); "Clássicos Vivos" (apresentação de textos de poetas antigos de variadas nacionalidades); "Subsídios de Crítica ou Textos e Pretextos para Discussão" (divulgação de trechos da teoria de poetas-críticos como Gertrude Stein, T. S. Eliot, Ezra Pound, entre outros); "Pedras de Toque" (seleção de exemplos do que o poeta considerava linguagem poética de alto nível); "Diálogos de Oficina" (divulgação de ideias autorais sobre poesia e crítica - trata-se da seção em que surgiram pela primeira vez, separadamente, os três ensaios que estudamos); "Fontes e Correntes da Poesia Contemporânea" (formação de uma galeria de autores considerados fundamentais para a nova poesia), "Evolução da Poesia Brasileira” (organização de uma história da poesia nacional desde o período colonial); e "Personae" (divulgação e comentário de novidades).
} 
de produção intelectual, foi a mesma: fomentar a busca por uma nova escrita poética no país, atualizar o repertório estético nacional, subsidiar o surgimento de uma nova crítica de poesia e contornar os problemas de que "Um jovem poeta brasileiro, como eu, queixa-se":

\begin{abstract}
[...] do nível infraginasiano, para não dizer primário, da maioria do que é publicado aqui em livros, jornais e revistas; das tolices que é forçado a ler e a ouvir a respeito de sua poesia (elogios ou não), a respeito da arte e dos poetas que admira; da falta de amor à poesia, do egoísmo e da vaidade que registra em muitos de seus colegas mais velhos, entre os quais raríssimo é aquele que forma escola, que realmente se interessa pelo progresso da língua e da arte vivem a pensar em self-promotion -; o jovem poeta queixa-se ainda da falta de profissionalismo econômico e ético, da péssima qualidade de quase toda a nossa crítica literária (sobretudo quando se mete a falar de poesia) de todos os tempos; um poeta jovem queixa-se, para resumir, de muita coisa (FAUSTINO, 1964, pp. 11-12).
\end{abstract}

Disposto a chacoalhar o estado de coisas da poesia brasileira, Faustino encontrou no contexto da sua produção um terreno muito mais fértil do que aquele das gerações anteriores, segundo ele mesmo afirma. Isso porque - e hoje é mais fácil vê-lo, com a distância crítica do tempo que se nos interpõe - os anos 1950, cujo início coincide com o início da vida adulta do piauiense, foram anos em que fervilhava o imaginário do progresso nacional e da transformação sociocultural. Não custa lembrar alguns eventos do período que justificam essa afirmação: o governo dos 50 anos em 5, a construção de Brasília, a aceleração da urbanização, as discussões sobre reforma agrária, a consolidação de vários dos principais cursos de graduação em letras do Brasil, a criação e a internacionalização da Bossa Nova, a ascensão das vanguardas do meio do século. Se, por um lado,

Os problemas devem ser os mesmos das outras gerações: dificuldades econômicas (ter de trabalhar, fora da literatura bem mais do que dentro, para ganhar o panem nostrum); falta de uma vida genuinamente artística, falta de emulação, falta de debates (no Brasil quase todos os escritores, quando reunidos, ou não tocam em problemas literários ou então, se falam de literatura, é da maneira mais vaga e leviana - discussões de personalidades, troca de elogios, gratuitas afirmações de valor ou de intenção, frases feitas, detestáveis mots d'esprit...); falta de revistas de cultura, falta de tradição filosófica, poética e crítica na língua, falta de um público inteligente, concorrência desleal (talvez não haja país no mundo com tanta gente errada em lugares errados) etc. (FAUSTINO, 1964, p. 11),

por outro, o jovem poeta brasileiro 
[...] congratula-se por pertencer a um país jovem e épico, a um povo amante, vigoroso, resistente, humano e amável como poucos outros, por ter nascido nesta época extremamente propícia à grande poesia, por falar uma língua potencialmente tão boa quanto qualquer outra e, em particular, por ver que as coisas, em nossa literatura, estão a olhos vistos mudando para melhor - está acabando o estrelismo, estuda-se mais e trabalha-se mais. Disso não tenho dúvidas (FAUSTINO, 1964, p. 12).

Sobre esse último excerto - que pode ser encarado como o registro de uma mudança em processo ou como um wishful thinking - certamente influem as discussões em torno da vanguarda da Poesia Concreta brasileira. Faustino escreve essas palavras em 1957, um ano após a criação oficial do movimento. O autor, que estava fielmente comprometido com a renovação da cena local, tinha entre as suas referências críticas alguns autores de língua inglesa, como Ezra Pound, e encontrava nos pares do concretismo, também referenciados em Pound, uma potente fonte de diálogo, bem como alguns dos melhores fomentadores da renovação desejada em direção a uma poesia mais integrada com as novas mídias, mais antenada com os experimentalismos das outras artes, mais inovadora linguisticamente e, a seu ver, finalmente emancipada das amarras que as leituras convencionais doutrinárias da tradição e da cultura representavam.

Os pares do concretismo, por sua vez, encontravam em Faustino um grande defensor e divulgador das ideias do movimento, um arauto de um modernismo poético diferente daquele de influência francófona, mais conservador, defendido pelos poetas da Geração de 45; alguém que, apesar da defesa e da divulgação do concretismo, por não ser integrante da vanguarda, sabia dialogar com vertentes poéticas não concretistas, servindo ele mesmo como uma espécie de mediador das ideias que surgiam de diversas matrizes vanguardistas e de outras mais convencionais também. Há de se pontuar, contudo, que os poetas do concretismo brasileiro julgavam o poeta Faustino insuficientemente comprometido com o experimentalismo e com a invenção que propunham. Para Augusto de Campos (2015), por exemplo, ele foi o "último versemaker". ${ }^{6}$ Para

\footnotetext{
${ }^{6}$ Versemaker, vale dizer, é um termo de cunho detrator, sendo usado em inglês para diferenciar os meros fazedores de verso dos bons poetas. No caso da atribuição do termo a Faustino, por parte dos poetas concretos, entra em jogo uma outra camada de sentido: eles estavam propondo uma poesia para além do verso, enquanto ele jamais teve a intenção de fazer poemas fora da tradição do verso melódico. Ainda que tivesse experimentado com o espaçamento das palavras na página e ainda que defendesse a narrativa de que o ciclo histórico do verso estava no fim, a poesia de Faustino e os seus manuscritos provam que ele era um artesão e crítico preocupado com a história e com os destinos da versificação.
} 
Haroldo de Campos (2006, p. 199), ele era "mais apegado à grande tradição clássica do que à 'tradição de ruptura' incessantemente vetoriada para o futuro". De fato, segundo o próprio Faustino (1964, pp. 81-83):

Tal era a situação da poesia brasileira no momento em que se fala em poesia concreta. [...] É para esses poemas que viemos pedir a atenção do leitor honesto desta página, cujo orientador - que escreve estas palavras - deixa esclarecido não ser, pelo menos até hoje, concretista, não tendo o menor interesse pessoal na experiência tentada por seus colegas de São Paulo e pelo sr. Ferreira Gullar. Apenas acontece que acredita nas seguintes coisas: 1. Que o "verso", no sentido em que a palavra tem sido empregada até agora, se encontra, no momento, em crise [...] 2. Que essa crise está formulada pelo menos desde o Mallarmé de Un coup de dés [...] 3. Que a solução para essa crise tentada por Mallarmé e retomada, de maneiras diversas, por um Apollinaire, por um Schwitters, por um Pound, por um cummings, é um caminho pelo menos dotado de logicidade e consistência e de harmonia com muitas coordenadas do nosso espírito de nossa época; chega mesmo a ser uma das únicas tentativas sérias de resolver a crise [...] 4. Que a poesia é, ao mesmo tempo, ideia, som e imagem; discurso, canto e padrão visual; [...] 5. Que a poesia brasileira necessitava, para tirá-la da pasmaceira em que ainda se encontra, de um movimento de vanguarda sério e vivificante; [...] 6. Que os srs. Décio Pignatari, Haroldo de Campos, Augusto de Campos e Ferreira Gullar já eram, antes do concretismo, os melhores poetas brasileiros aparecidos depois de João Cabral de Melo Neto; [...] 7. Que a experiência concretista, na melhor das hipóteses, poderá salvar a poesia brasileira do marasmo discursivo-sentimental em que se encontra [...] 8. Finalmente, que os concretistas, como artistas de vanguarda, têm todo o direito, e quiçá mesmo o dever, de serem extremistas, combativos, proselitistas, exclusivistas etc.

A concordância que podemos identificar entre a visão crítica de Faustino e a dos irmãos Campos tem muito a ver com um projeto de renovação estética com vistas ao aspecto estrutural do sistema literário e ao ensino institucional de literatura no Brasil. Ambas as partes nutriam interesse portrazera forma poética para ocentro dodebateedoaprendizado de poesia. Propunham uma abordagem estética/sincrônica7 baseada no

\footnotetext{
7 "A descrição sincrônica considera não apenas a produção literária de um período dado, mas também aquela parte da tradição literária que, para o período em questão, permaneceu viva ou foi revivida. Assim, por exemplo, Shakespeare, de um lado, e Donne, Marvell, Keats e Emily Dickinson, de outro, constituem presenças vivas no atual mundo poético da língua inglesa, ao passo que as obras de James Thomson e Longfellow não pertencem, no momento, ao número dos valores artísticos viáveis. A escolha de clássicos e sua reinterpretação à luz de uma nova tendência é um dos problemas essenciais dos estudos literários sincrônicos" (JACKOBSON apud CAMPOS, 2013b, p. 82).
} 
conceito de paideuma, ${ }^{8}$ tendo em vista preencher lacunas bibliográficas e preparar melhor os futuros artesãos da palavra para problemas estéticos relevantes. Opunham-se à crítica biográfica e historiográfica-diacrônica ${ }^{9}$ que vigorava no Brasil, desprezando grande parte das informações que se ensinavam nas escolas por considerarem-nas "itens obsoletos" (POUND, 2006, p. 161). Também compartilhavam, Faustino e os outros, a influência poundiana, o reconhecimento da crise do verso mallarmeana, o espaço-tempo joyceano da "contenção do todo na parte" [allspace in a notshall] e do "fluxo polidimensional sem fim" (CAMPOS, 1981, p. 37), entre outros vieses do pensamento sobre o fenômeno poético que se faziam notar com muito vigor no meio do século XX.

Como é possível observar, a posição do poeta e a do crítico Faustino são díspares. O entusiasmo quase que irrestrito do autor pelas ideias da vanguarda concretista não se reflete na sua escrita. Ele desejava um ambiente esteticamente mais efervescente onde o novo criador, incluindo ele, pudesse desenvolver projetos de modo mais consequente - mas isso não implicava aderir a uma ou outra das vanguardas que ajudava a divulgar, nem reproduzir criativamente as ideias que defendia como importantes para a renovação da poesia. Assim, se o crítico Faustino, em diversos momentos, portou-se como um guerrilheiro cultural do concretismo, o Faustino poeta sempre esteve interessado pelo verso (aquela instituição cuja crise ele mesmo propalou), pelo debate com a tradição, pelo discursivismo e pelo sentimentalismo lírico. As discussões concretas serviam-lhe para repensar os seus modos de escrever e os da tradição poética, não para superá-los no pós-verso, no pós-lírico, no pós-discurso (como, no entanto, ele mesmo chega a defender em textos críticos e jornalísticos).

\footnotetext{
${ }^{8}$ Faustino e os poetas concretos empregaram o conceito de paideuma a partir do sentido a ele atribuído por Ezra Pound (2006, p. 161): "a organização do conhecimento para que o próximo homem ou geração possa achar, o mais rapidamente possível, a parte viva dele e gastar o mínimo tempo com itens obsoletos".

9 "É necessário criar um corpus da literatura brasileira para a integração curricular, e é nesta emergência que - como salientou uma vez Décio Pignatari - o historiador literário brasileiro, em lugar de proceder como Confúcio na anedota exemplar recontada por Ezra Pound (isto é, reduzir três mil odes a trezentas, para o fim de definir uma antologia realmente básica), infla uma dezena de bons autores em uma centena ou mais de literatos subalternos" (CAMPOS, 2013a, pp. 15-16).
} 


\section{O AUTOR E SUA OBRA}

A obra de Faustino é usualmente dividida em fases, na terminologia de Augusto de Campos (2015), ou em momentos, na de Benedito Nunes (2002). A esse respeito faz-se notar, no simples gesto de divisão da obra em partes, o quão prolífico Faustino foi e o quanto diferiu de si mesmo ao longo dos seus poucos anos de escrita. Como os recortes propostos por um e outro apresentam mais coincidências que contrastes, utilizaremos o termo fases, de Augusto de Campos, sem grande prejuízo em relação à leitura de Nunes.

A primeira fase da obra de Faustino abrangeria todo o seu período de formação até 1955, ano da edição de $O$ homem e sua hora, seu único livro publicado em vida. Ela seria uma fase de manifesta preocupação do autor com a materialização do conhecimento e dos métodos retirados da tradição (da cultura clássica, da mitologia greco-latina e das artes plásticas) em uma escrita modernizada pelas experiências do seu tempo e das décadas que lhe antecederam (a partir do corte da Semana de Arte Moderna de 1922). E abrangeria seus primeiros escritos, nos quais encontramos misturados o desejo de dar vazão à erudição clássica acumulada e ao impulso modernizante de quem desejava fazer-se escritor do tempo presente.

A segunda fase estaria compreendida entre 1956 e 1958, intervalo de maior aproximação do escritor com as ideias da Poesia Concreta. $\mathrm{Na}$ poética, é caracterizada pelos poemas mais experimentais - nos quais, por exemplo, passa a utilizar a disposição das palavras na página a favor da criação de novos sentidos para os seus versos, algo que se nota, exemplarmente, em seu "Soneto (bronze e brasa na treva)". Na crítica, é caracterizada pela expansão do repertório cultural em um laboratório ${ }^{10}$ público: coincide com o período de fomento da página "Poesia-Experiência" no Suplemento Dominical do Jornal do Brasil, na qual buscou estudar, traduzir e divulgar textos de estéticas que julgava relevantes para aprimorar a própria produção e a de seus contemporâneos. Suas premissas, ao longo dos anos de atividade da página, comungavam

\footnotetext{
${ }^{10}$ Ele prefere "escrever num laboratório a escrever num templo" (FAUSTINO, 2003, p. 189). A ideia de laboratório, também poundiana, é ainda retomada pelos irmãos Campos como modo ideal de desenvolvimento estético: o fazer no calor da hora, o sucesso através da tentativa e erro, a performance pública dos métodos em desenvolvimento, a flexibilidade para mudar ideias e argumentos de acordo com as exigências dos novos tempos etc.
} 
com aquelas de Ezra Pound e Oswald de Andrade que vinham sendo reformuladas pelos poetas concretos: era necessário construir um paideuma, uma visada sincrônica da literatura, uma organização do passado com vistas a dispor a informação viva da tradição de modo que o novo poeta a encontrasse sem perder tempo com conteúdos ociosos; e era necessário adquirir, antropofagicamente, via tradução inclusive, as novidades estéticas do outro/estrangeiro, reelaborando-as segundo as demandas das culturas locais.

A terceira fase - esta interrompida pela morte -, constitui-se por um interesse oposto ao da primeira, a saber: a busca de integrar o moderno na tradição. Essa busca foi operada, pelo autor, da seguinte forma: a partir das ideias, dos procedimentos, das ferramentas e das percepções que vinha formulando ou tomando de empréstimo em seu laboratório público por meio da crítica-tradução-criação da segunda fase da sua obra, buscava plasmar a novidade estética no modo de ser da cultura. Não mais se tratava de atualizar o passado, de dar-lhe um aspecto de novo segundo o lema poundiano do make it new, mas de fazer do novo, tradição, com a consciência de que a nova experiência é rapidamente incorporada aos repertórios da arte vindoura e com o desejo de fornecer uma obra-base para os novos tempos. Tal confluência de técnicas, interesses e referências visava à produção de um opus magnum, um poema-vida, sua obsessão, cujo longo formato seria inspirado nos Cantos de Pound e na Invenção de Orfeu, de Jorge de Lima.

Essa obra maior que Faustino gestava no momento da sua morte consistia em um experimento de fragmentos poéticos. O projeto do autor era escrever fragmentos ao longo de décadas e, de tantos em tantos anos, reuni-los em "Cantos" a serem publicados em livros. Com esse experimento, o que buscava (ou, pelo menos, o que alegava buscar) era configurar uma linguagem poética total, que pudesse ser comum a diversas artes e formas de expressão artística e cujo modelo pudesse ser exportado para outras formas literárias clássicas - por exemplo, o teatro. Seu poema-vida deveria servir para alimentar a poesia brasileira, que ele julgava carente de obras de envergadura e ambição.

Alguns ensaios publicados esparsamente, sobretudo os posteriormente recolhidos na Coletânea 2, seriam a contrapartida crítica do projeto dos cantos/fragmentos. Enquanto Faustino realizaria, na poesia, uma espécie de épico moderno, um conjunto de livros que alimentaria as gerações futuras com uma grande referência técnica e 
criativa, ele queria produzir, na crítica, um livro como o $A B C$ of Reading de Ezra Pound, como o Cartas a um jovem poeta de Rainer Maria Rilke, ou como um tratado poético que servisse de obra básica à formação dos artistas vindouros. Desse projeto de iniciação crítico-teórica à literatura, o qual, assim como o dos cantos, foi abortado pelo acidente de avião, restam-nos os ensaios publicados na seção "Diálogos de Oficina" da página "Poesia-Experiência" - os quais apresentam clara unidade e coerência interna, tendo sido certamente projetados como a base de um projeto maior inacabado.

No texto de apresentação da Coletânea 2, Assis Brasil (1964, p. 10) afirma, sobre os três primeiros ensaios do volume, que, "[p]or tratarem de assunto referente à Poesia e ao Poeta, como o próprio Mário sempre admitia, têm um sentido didático, e seu endereço certo é o jovem poeta brasileiro". É sobre eles que passaremos a falar, após as breves considerações da próxima seção, que trata da constante antevisão da morte na obra de Faustino e da sua defesa do caráter inacabado/fragmentário dos próprios escritos como uma estética singular com potencial renovador.

\section{O ASSÉDiO DA MORTE: A INTERRUPÇÃO, A ESTÉTICA DO FRAGMENTO E OS ENSAIOS}

Como que antecipando a interrupção das suas obras (o assédio da morte e a incompletude são-lhe temas recorrentes), Faustino (2003, pp. 489-490) diz, em "Um ano de experiência em poesia", balanço do primeiro ano da sua página "Poesia-Experiência" (1956-1957):

$\mathrm{O}$ que pensamos. $\mathrm{O}$ que escrevemos, nesta página. $\mathrm{O}$ que escrevemos, em poesia. [...] nossa obra, mais pessoal, de poeta a caminho, de poeta que se faz, que não está feito, que é. [...] E poemas nossos - aspectos, ainda que marginais, de nossa poesia em elaboração, em transformação, em avanço e recuo, em experimentação, em autorretificação [...] Depois de O homem e sua hora (espécie de relatório de meia dúzia de aprendizados poéticos), nossa presente "fase", como poeta: especialmente imprópria para publicação; ausência de produtos acabados [...] ausência de linha - passagem de linha, hesitações, apalpadelas.

O poeta relatava que o seu regime de produção foi-se tornando parcial no período que, como vimos, marca a passagem entre a segunda e a terceira fases da sua obra. Ele passa a trabalhar nos interstícios de uma busca linguística, de uma afinação estética, e não trata a poesia como um 
resultado, como um produto íntegro de um encontro, mas sim como um instrumento do processo, como o veículo da própria busca.

Todo poeta digno de ser como tal considerado pelo povo (que nele ver [sic], por bem ou por mal, um dos seus guias e porta-vozes) considera sua vida como um processo ininterrupto de aperfeiçoamento. Nesse processo entra a poesia como instrumento principal (FAUSTINO, 1964, p. 22).

Embora tenham ficado inacabados, os textos da sua terceira fase também precisam ser avaliados em relação consigo mesmos e com o seu tempo, evitando o uso de paradigmas imaginários ou míticos para o autor precocemente falecido. Afirmamo-lo porque os "fragmentos" de poema legados eram pensados não como partes carentes, mas como as próprias realizações de uma estética do fragmento. Em outras palavras, elas eram as células, projetos em si, não etapas, embora também fossem parte de um projeto maior que não se realizou, o livro-compilação de fragmentos - o qual, segundo Benedito Nunes (2002, p. 41), seria

\footnotetext{
[...] escrito através de vários poemas, seria a forma total nascendo do intercurso de formas parciais, que cresceria, totalizando-se, num processo de recorrência, no qual cada parte ensejasse o todo e o todo preexistisse em cada parte. [...] Essas formas parciais, [...] "fragmentos", são [...] momentos da experiência do poeta no tempo e com o tempo. Mário Faustino, conforme dispôs um ano antes de morrer, estava decidido a publicar de cinco em cinco anos [...] fragmentos.
}

Consideramos que tal pensamento acerca dos fragmentos como forma desejada, como finalidade em si, deve servir também para pensar os ensaios do autor - como já dissemos, a contrapartida crítica do projeto poético. O objetivo grandioso de Faustino era implicado nas formulações crítico-teóricas das resenhas edos ensaios queele ia publicandoquasecomo testemunhos, no calor da hora das pesquisas e dos debates. "Momentos" da experiência do poeta no tempo e com o tempo, essas formas parciais, sobretudo as recolhidas na primeira parte do livro Coletânea 2 ("Para que poesia?", “O poeta e seu mundo" e "Que é poesia?”), são os registros mais relevantes de uma poética-crítica inteiriça e, simultaneamente, em formação.

Os ensaios da Coletânea 2 são o ponto nodal de um esforço construtivo mais sistemático em prol de uma nova poesia/linguagem. O que eles apontam constitui uma proposta não apenas de poesia e muito menos de uma linguagem exclusivamente pessoal: o que estava em jogo era um novo regime de arte e cultura. Nos textos, Faustino formula métodos de 
produção, formas de visibilidade para a poesia e, por fim, ainda postula modos de conceituação do que seja a poética, de modo que os três primeiros se complementam: "Para que poesia?", "O poeta e seu mundo" e "Que é poesia?” abordam a relação do poeta com o mundo (regimes de visibilidade), da poesia com as coisas/os objetos (regimes de produção) e do próprio ser da poesia com o pensamento (regimes de conceituação).

A ideia dos textos do compilado é constituir uma pedra fundamental, um princípio de onde partiriam os jovens poetas brasileiros vindouros, como já dissemos. Seu objetivo era que, em conjunto, os textos fossem úteis e amplamente aceitos, que interferissem no contexto da produção nacional, rechaçando o academicismo típico de textos dessa estirpe para poder comunicar e influenciar sem grandes restrições. Tal preocupação com a formação cultural e estética mais ampla das novas gerações, vale dizer, não é individual ou aleatória. O contexto histórico dessas motivações talvez nos sirva para compreender a postura, digamos, engajada e grandiloquente. O Brasil lançava-se, naquele momento, como país do futuro, tendo como paradigma máximo Brasília. O ambiente da cultura era o de uma nova onda modernista e borbulhavam propostas para a atualização social, política e cultural brasileira. Em todas as artes, pululavam movimentos importantes: a arquitetura de Niemeyer, a Poesia Concreta dos irmãos Campos e Décio Pignatari, a Bossa Nova de João Gilberto e Tom Jobim etc. Aquela necessidade de criar um corpus da literatura brasileira, que citamos em nota de rodapé anteriormente nas palavras de Haroldo de Campos, foi sentida por Faustino de modo particular: era preciso criar um corpus de estéticas inovadoras que fundamentasse a arte do presente-futuro do país do futuro.

\section{PARA QUE POESIA? - PRIMEIRO ENSAIO DOS DIÁLOGOS DE OFICINA}

Faustino estimulava e defendia publicamente, como já dissemos, a vanguarda da Poesia Concreta. Na sua percepção, ela empreendia "um esforço em prol da solução de alguns dos aparentes impasses estéticos de nossa época" (FAUSTINO, 1964, p. 71). De fato, seus componentes incrementavam o repertório poético brasileiro com traduções e experiências até então inéditas, por um lado, e chacoalhavam a cena cultural, por outro - a rigor, faziam exatamente as coisas que ele também pretendia fazer, embora por outros meios. Compartilhando com eles referências críticas, sobretudo Ezra Pound, para quem os poetas deveriam 
ser "antenas da raça”, o poeta-crítico enxergava nos gestos da vanguarda um verdadeiro movimento de reinterpretação poética em prol de uma responsividade arte-mundo em que a sociedade brasileira era propositora, não apenas receptora, de ideias e informações culturais.

No primeiro ensaio da Coletânea 2, "Para que poesia?", desenvolve-se uma forma de pensar a relação poeta-mundo como altamente funcional, na medida em que o estado de coisas e o estado da arte seriam (ou deveriam ser) correlatos. A linguagem cumpriria um papel indispensável para o avanço social, e os poetas seriam os guardiões da renovação e da aprimoração dela:

O bom poema exerce desde logo, com ser bom, um papel importantíssimo ajuda a língua a manter-se num alto nível de expressividade [...] sem o qual - isto é, sem uma linguagem eficiente, precisa, maleável, clara, econômica (e bela!) - uma sociedade dificilmente poderia desenvolver-se. [...] um idioma apto contribui sempre para uma nacionalidade culturalmente mais criadora, mais forte economicamente, mais segura e mais livre politicamente (FAUSTINO, 1964, p. 30).

A exigência de engajamento do escritor em prol de tal responsividade, inclusive, levava-o a afirmações provocativas e categóricas - típicas, é verdade, do formato jornalístico -, tais quais:

O sr. Carlos Drummond de Andrade só age poeticamente através dos poemas que publica. Não escreve a sério sobre poesia. Não faz crítica séria de livros de poesia. [...] É, quando muito, um master. Não é um "inventor", não é um impresario. Nunca seria um Pound, nem mesmo um Eliot (FAUSTINO, 1976, p. 210).

Ou, então, numa comparação de Drummond com João Cabral de Melo Neto:

O sr. João Cabral de Melo Neto sabe que a poesia tem problemas culturais, políticos, éticos, estéticos [...] mostra-se mais vivo (como era de esperar), atua mais no sentido de puxar o cordão da poesia brasileira em suas evoluções por outras praças. [...] É, pelo menos no momento, mais inventor que o sr. Drummond, mas nada tem de condottiere poético de que necessitamos. Faz sua "vanguarda" em casa (FAUSTINO, 1976, pp. 210-211).

O nível de participação do poeta (aqui, desejado como poeta-crítico e militante da linguagem) em relação à sociedade é medido pela interpretação específica que Faustino faz da função estética da literatura. Ele não se refere a uma participação folhetinesca ou político-partidária, 
mas a uma participação esteticamente interessada - como, por exemplo, Dante teria sido poeta "interessado".

Poesia diretamente interessada, senhores, só em grandes situações históricas: Miguel Hernández na Guerra Civil, Paul Éluard líder da resistência. Drummond aqui, lendo jornal e ouvindo rádio, a tremer por Stalingrado. Maiakovski na industrialização soviética. Ou então, toda grande poesia, que toda grande poesia é obviamente interessada: Milton, Dante (FAUSTINO, 1964, p. 77).

Para Faustino, a poesia deve ser, sobretudo, de boa qualidade, deve ser esteticamente boa. Grande poesia é, obviamente, interessada, já que a militância é estética. A má poesia é tão grave, ou tão pior, quanto militar por uma causa errada, e faz tão mal quanto ideologias políticas maléficas. Há de se pontuar que a correção e o ideal que Faustino defende não têm relação com valores extrínsecos ao literário, mas intrínsecos: trata-se de uma questão de poesia, de linguagem artística. A contribuição social do poema é ser bom, é fazer a linguagem produtiva, bela e instrutiva, produto impactante, condensado de ideias e experiências sensoriais com as coisas do mundo, com o destino de se eternizar.

- [...] Acredito mesmo que um mau poema já é, em si, um perigo social, um mau que seu autor faz à sociedade.

- Sim. O mau poema degrada a língua, e uma língua que decai provoca necessariamente - como diria Pound - a decadência da sociedade que a fala. Evidentemente, trata-se de uma relação de causalidade recíproca (FAUSTINO, 1964, p. 30).

A promíscua relação da poesia com o idioma, para Faustino, reside no fato de que aquela é a manifestação mais avançada deste. Ela está, desse modo, na ponta de lança de toda comunicação comunitária. Impactar uma sociedade/comunidade, aprimorá-la, propor ideias verdadeiramente afinadas com ela, tudo isso não se daria pela busca de verdades políticas externas ao estético (por exemplo, pela orientação da arte em direção ao fascismo, ao marxismo ou ao liberalismo), mas pela (re)configuração das coisas da realidade em discurso, redistribuindo os elementos do sensível de forma bela, esteticamente atraente e linguisticamente eficaz, capaz de consolidar ideais ou ideários de uma sociedade - a qual ou vive profundamente esse modo de ser tornado arte, ou o viverá pela experiência estética, caso a obra seja boa e permita essa experiência estética exemplar. À medida que alcança esse ideal, 
[...] a grande poesia está sempre contribuindo ativamente para a formação de utopias (o largo terreno de onde brotam as ideologias e sistemas de vida), para formulação de ideias, para a criação de um clima social, para alimentação de um movimento revolucionário etc. (FAUSTINO, 1964, p. 29).

Por conta dessas responsabilidades e atribuições da poesia, o poeta precisa ser alguém especial. Não se constrói uma utopia fazendo arte por arte, sem interesse social, filosófico e sociológico, sem sujar-se na relação com o mundo e com o contexto que cerca o artista - artista que

[...] não pode esquecer os fenômenos psicológicos e sociais, nem as novas direções que vão tomando, paralelamente à poesia, a psicologia, a antropologia, a sociologia, a economia, a história, a filosofia etc. [...] é essa preocupação pelo todo que justifica a parte, tendência à qual não pode alhear-se o poeta. Este, cada vez mais, é obrigado a ver sua poesia como forma de cultura, expressiva, tanto de seu povo como de seu meio, como de seu tempo (FAUSTINO, 1964, pp. 29-30).

Ele sabia, apesar disso, que tais modos de pensar a arte em relação à verdade e ao modo de ser de um povo levaram às - ou vieram a se identificar com as - ideologias mais brutais dos governos mais catastróficos do século. A arte nazista propunha-se como modelo moral e de eficiência de uma sociedade a ser implantada; a arte soviética havia sufocado as linguagens de vanguarda a tal ponto que Maiakovski, símbolo das vanguardas do início do século XX, foi levado ao suicídio. Consciente desses fatos, ele alerta:

- O poeta contemporâneo tem de ser perigoso como Dante foi perigoso: uma força respeitável frente às demais forças sociais [...]

- Todavia não te hás de esquecer dos perigos que essas teses encerram.

- Evidentemente. Toda premissa certa [...] deu sempre lugar a conclusões erradas, sempre mais numerosas e mais fáceis de extrair que as exatas (FAUSTINO, 1964, p. 30).

Seu modo romântico de pensar poesia-verdade-mundo não estava interessado pela produção de estéticas como as que, servindo como instrumento de politização ou de estetização do poder e das massas, participaram ativamente dos autoritarismos do século XX. Seu interesse político relativo à poesia era pela função estética e linguisticamente exemplar dela: os poemas em si, tomados na materialidade da linguagem; os poemas em diálogo com o mundo de coisas entre as quais eles circulam; 
o poema em diálogo com o universo afetivo (local e temporal) do poeta. Só assim a poesia pode produzir uma sociedade melhor, a qual não pode ser jamais exclusiva ou excludente, muito pelo contrário: "todo o universo natural, social e individual constitui o objeto desta percepção. De passagem, pode-se lembrar não mais caber qualquer discriminação nesse sentido: tudo pode ser objeto, não só da percepção como da expressão poéticas" (FAUSTINO, 1964, p. 41). Sua ideia de aprimoramento da sociedade via arte era inclusiva, democrática e abrangente, não exclusiva, autoritária e impositiva.

Rechaçando os desdobramentos de ideias românticas equivocadas de arte-sociedade, Faustino insiste em formular a sua própria proposta crítica para essa relação:

- Creio que a questão pode ser encarada de duas maneiras, que poderíamos com
certa boa vontade chamar de passiva e ativa. No primeiro caso, a poesia serve
à sociedade testemunhando-a, interpretando-a, registrando as diversas fases
espaciais e temporais de sua expansão e evolução. Nisso a poesia é como toda
arte: um documento vivo, expressivo, do estado de espírito de certo povo, em
dada região, numa época determinada. A poesia, aliás, é incomparável quando
registra - com a capacidade condensadora e mnemônica de que só ela é capaz-
certas nuanças de ponto-de-vista, de atitude, de sentimento e de pensamento,
individuais como coletivos, nuanças essas que, muitas vezes, são bem mais
expressivas de um povo e de uma época do que os grandes acontecimentos
(FAUSTINO, 1964, p. 24).

- [...] o outro lado da questão, a maneira como a poesia age sobre o povo, a certa altura de sua evolução social. [...] Aludo ao poema agindo sobre o povo, da mesma maneira que um comício, um discurso, um editorial, ou a notícia de cataclismas e revoluções (FAUSTINO, 1964, p. 26).

É desse modo que se organizam suas propostas sobre a função social da poesia no primeiro ensaio da coletânea. Segundo elas, o poeta é um ator de transformação da sociedade e age através da linguagem e da cultura. Ele é o criador das linguagens que a transformam, e a sua capacidade de percepção/expressão apurada das nuanças expressivas de um povo e de uma época em transformação é o que permite o desempenho da função transformadora. Com isso, Faustino encaminha os seus dois ensaios seguintes, nos quais definirá a condição do poeta e o conceito de poesia capazes de viabilizar a funcionalidade projetada por este primeiro texto. Em uma espécie de suma de "Para que poesia?", ele declara:

[...] a poesia é instrumento de realização existencial do próprio poeta, que, através dela se organiza, se afirma e se harmoniza com o resto da humanidade 
e com o universo: a poesia age sobre o leitor ou ouvinte, individualmente considerado, ensinando-o (comunicando-lhe a experiência vivencial do poeta), deleitando-o (comunicando-lhe a satisfação de permanecer vivo e a alegria imanente a toda coisa bela) e comovendo-o (comunicando-lhe o sentimento da importância de viver, e provocando-lhe aquela catarse característica de quem experimenta uma obra-prima). A poesia age sobre a sociedade na qual se manifesta, testemunhando e criticando (no sentido profundo) uma parte da humanidade ou toda a humanidade de uma certa época, estimulando e provocando essa humanidade a transformar-se, criado utopias e alimentando ideologias e, finalmente, tornando sua língua mais apta e por isso mais bela. [...] É preciso sempre distinguir o nível, o campo, ético, político, estético, em que louvamos ou combatemos um poema. Se não fizermos, nossa crítica será, em vez de construtiva e esclarecedora, destrutiva e obscurantista (FAUSTINO, 1964, pp. 33-34).

\section{O POETA, O SEU MUNDO E O CONCEITO DE POESIA - SEGUNDO E TERCEIRO ENSAIOS}

As propostas por uma nova poética, em prol de uma nova sociedade, partem e precisam partir de uma concepção de poesia apropriada. O segundo e o terceiro ensaios, "O poeta e seu mundo" e "Que é poesia?", fundamentam os termos básicos dessa poética. Operando uma definição por exclusão, Faustino utiliza como parâmetro o paradigma da prosa, e o faz de modo bastante semelhante ao de Paul Valéry (2011) no ensaio "Poesia e pensamento abstrato", publicado originalmente em 1936, no qual o poeta francês compara a poesia com a dança e a prosa com a caminhada. De um lado, Faustino situa o autotélico, o intransitivo, a sofisticação; de outro, o instrumental, o transitivo, o trivial.

É prosaico o arranjo de palavras em padrões (cuja forma gráfica, e cujo ritmo, mais ou menos irregulares, não nos interessam ainda) que analisam, descrevem, ilustram, glosam, narram ou comentam o objeto: é prosaico o discurso sobre o objeto (ser, coisa ou ideia). E, correspondentemente, consideraria poético o arranjo de palavras em padrões (cujo aspecto formal auditivo ou visual - repito, ainda não entra em consideração) que sintetizam, suscitam, ressuscitam, apresentam, criam, recriam o objeto; é poético o canto, a celebração, a encantação, a nomeação do objeto (FAUSTINO, 1964, pp. 58-59).

Ele se refere à poesia como um discurso que não quer simplesmente comunicar, mas sim apresentar/apresentar-se, enquanto a prosa faz comentários sobre algo, transmite ideias independentemente do modo de apresentação da mensagem. O poético, para Faustino, reside num certo autotelismo - a linguagem se fazer notável -, no caráter insubstituível dos 
termos e dos jogos linguísticos da fórmula original: o poético é idêntico ao modo de configuração do poema, não se dissocia dele. É uma questão, portanto, material, relativa ao artifício, à arte do criador de linguagens, e indiscernível do construto linguístico originalmente formulado.

Nessa diferenciação básica, a poesia é um termo desligado da ideia do verso. Ela não se define por ele. O verso pode ser prosaico, o poema pode ser verbivocovisual. A poesia é o construto, independentemente dos materiais utilizados na obra. Esse desligamento faz-se importante, pois Faustino estava elaborando um método de aproximação da poesia às coisas, o qual, se remete ao imitativo, ao mimético do esquema clássico aristotélico, vai além. Demasiadamente preocupado com a realidade e com uma responsividade da arte, ele busca pensar formas de elidir linguagem e objetos do real, o que o leva a pactuar uma nova relação poeta-mundo e poesia-objetos: o poema é um objeto de linguagem que usa palavras, as quais têm o poder de reconfigurar os objetos do mundo físico em um novo mundo, o do poema.

\begin{abstract}
Sugiro, tão somente, ser o principal objetivo da linguagem poética a criação (ou recriação, repetindo) de um objeto - ou de um conjunto de coisas, seres, ideias que sob a forma de palavras-realidades se reúnem, através de todas as conotações possíveis, para formar um complexo, um objeto novo: o poema (FAUSTINO, 1964, p. 62).
\end{abstract}

Poesia é como a música e outras linguagens artísticas concretas, na concepção de Faustino, enquanto a prosa abdica dessa concretude da linguagem para comunicar uma ideia; o poético, portanto, não teria de ser compreendido, mas percebido - como um vaso, uma fachada, uma dança. Ele se interessava pelas poéticas consideradas relevantes à narrativa da Poesia Concreta (as de Pound, Mallarmé, Cabral, entre outros), mas valorizava-as por motivos próprios, compreendendo-as no gesto mesmo da luta pela transformação do poema em objeto-mundo, íntegro em si e autônomo, porém sempre em relação com a organização das coisas do mundo nomeadas nele. Não lhe interessava, como poeta e como tutor das gerações vindouras, que fosse perpetuada como valor do mundo-poema futuro a exclusão das referências ao mundo sensível. Não lhe interessava o curto-circuito concreto - o do poema cujo referente é a linguagem do poema -, embora os experimentos radicais com a materialidade da linguagem fossem fundamentais para pensar o conceito de poesia que Faustino queria formular. 
O poeta-crítico propunha, para as gerações futuras, o desafio de criar poemas cujo objetivo fosse apresentar-se na condição de coisas, com a máxima condensação de aparatos materiais da linguagem e, simultaneamente, com a máxima condensação de informações de coisas do mundo sensível externas ao poema; tudo isso no mínimo de discurso. Apresentar(-se), e não convencer ou comunicar como a prosa. Queria propor poemas como dispositivos de linguagem formuladores de objetos linguísticos, não necessariamente concretos ou verbivocovisuais, nem necessariamente em versos metrificados ou em verso livre. Esse seria o exercício poético por excelência. A matéria poética, por sua vez, seriam as coisas do mundo - como já dissemos, objetos simples, nuanças do cotidiano dos povos; o poema-mundo íntegro, de linguagem, em profunda relação com o mundo das coisas como ele se nos apresenta.

A artesania que Faustino tentou delinear, nesses ensaios, pressupõe uma ressignificação poética do objeto a partir da sua desfuncionalização processo em que se extrai a carga simbólica, política eafetiva da coisa/objeto em questão, e, posteriormente, opera-se uma recontextualização verbal dessa mesma coisa. O processo todo seria o de uma retroalimentação, de uma geração circular objeto-palavra-objeto; dessarte o poeta, como figura intermediadora, deve ser dotado de uma percepção de mundo e de uma habilidade de expressão linguística fundamentais.

[...] um homem dotado de certa capacidade de percepção e de expressão, ambas verbais (assim como tanto a percepção como a expressão específicas de um músico são mais uma questão de sons), que o tornam especialmente apto para harmonizar - intrinsecamente e em relação ao outro - os dois universos: um tangível - natureza e sociedade - outro intangível - o das palavras em todos os seus aspectos de som, ideia e imagem (FAUSTINO, 1964, p. 35).

A preocupação de Faustino não é com fazer poemas-objeto ao modo concreto - a concretude da linguagem não é monopólio de uma vanguarda. O verbivocovisual, para ele, é um fato dado da arte, éa realidade concreta da existência dela - realidade que, por conta de um certo predomínio histórico da interpretação semântica na abordagem da crítica, teria sido ignorada em nome da "mensagem" desencarnada. Ele debate-se com a necessidade de criar uma linguagem, ou seja, uma carnadura verbivocovisual que seja capaz não de comunicar a totalidade do funcionamento das coisas, mas de conformar objetos de linguagem que condensem, em seres de linguagem, as histórias, as relações funcionais e as utilidades de certos objetos/coisas em relação com outros objetos/coisas ou com indivíduos. Nesse sentido, 
Faustino pergunta: "Mas que providências deverá tomar o poeta para alcançar esses fins, isto é, para que possa exercer plenamente seu papel de traço-de-união entre os três elementos permanentemente agônicos: o próprio poeta, o universo (natural e social) e as palavras?" (FAUSTINO, 1964, p. 36). Na sequência, responde:

É preciso frisar, aliás, que os dois aspectos - percepção e expressão - somente se distinguem para efeito de argumentação: na realidade são simultâneos, não havendo nem mesmo, a propriamente falar, uma relação de causa e efeito, ou de sinal e sentido, entre uma e outra coisa (FAUSTINO, 1964, pp. 35-36).

Concretude do poema e mensagem abstrata são simultâneos; o objeto linguístico é tão objeto quanto os objetos do mundo de que se fala. Para ele, tratava-se de pactuar uma mediação entre mundo e palavras de maneira mais atenta à concretude destas, com vistas à evolução do verso - matéria que, se não era a detentora exclusiva do discurso poético, pelo menos era a principal. Faustino estava pensando um passo adiante em relação à poesia concreta e vislumbrava caminhos para a criação/crítica do verso após a explosão dele pelos experimentos do não verso.

Podemos dizer que o poeta-crítico Faustino estava interessado em confluir dois regimes de pensamento sobre a arte: o romântico (uma arte capaz de dizer e ser a verdade de um povo) e o linguístico-científico (uma arte material, analítica, que diz de forma objetiva e contida o mundo que se dá à percepção, o mundo dos fenômenos). Tentando unir religião e ciência, abstração e fenômeno físico, sua iniciativa apresenta inevitáveis contradições e belas sacadas. Entre estas, a sua proposta de aproximação direta ao objeto:

Antes de tudo o poeta deveria tornar o seu campo de percepção o mais amplo e mais profundo possível: procurar ver num conjunto o mais vasto e o mais pormenorizado universo físico que o cerca - considerando, em particular, aquela parte do universo que lhe cabe mais de perto (sua cidade, sua região, seu país) - e o meio humano (presente e passado, atualidade e história) onde cotidianamente age e reage psicológica e socialmente - destacando, outrossim, aqueles que ama diretamente, mais sua família, mais seus camaradas de estudo ou trabalho, mais sua classe, mais seu povo (FAUSTINO, 1964, p. 36).

A máxima condensação de recursos deveria, assim, ser aliada à máxima concentração de conteúdos das mais variadas ordens (psicológica, social, geográfica etc.) Essa ideia, demasiado abstrata e idealista - é claro que qualquer escritor deseja dizer o máximo de coisas em sua obra sem cair no caos da escrita -, conta com uma tentativa de explicação mais ou 


\section{menos pedagógica sobre os procedimentos capazes de tornar mais eficaz a percepção necessária a toda condensação.}

[...] o poeta precisa conhecer-se a si mesmo; disciplinar seus mecanismos de raciocínio, de modo que possa tornar-se objetivo, imparcial, sem preconceitos, sem tendências arbitrárias - tudo isso sem que fique prejudicada aquela "simpatia" de que já falamos; agrupar a um tempo a sua percepção do pormenor e do conjunto: desenvolver sua mente no sentido das ideias em ação, da visão total do mundo, do sentimento local da época, do "sentir com" de seu povo; procurar perceber o máximo através das imagens mesmas em que sua percepção será mais tarde expressada, mostrando as relações e distinções entre os objetos do conhecimento poético; procurar "conhecer poeticamente" o mundo - e não simplesmente conhecê-lo filosófica, científica ou misticamente (FAUSTINO, 1964, p. 38).

Dotado desse preparo, o poeta estaria capacitado a perceber tanto a vida própria (influenciada pelo conjunto) quanto a do conjunto (influenciada pelas partes) dos objetos, com a capacidade de percepção necessária para apresentar essas redes de relação com os seus poemas. O papel do artista seria, no final das contas, trazer os objetos dados à percepção, os objetos diários, para a poesia.

- [...] Refiro-me à capacidade que tem o artista, em geral, e em especial o poeta, de perceber seu objeto, cada objeto, em sua quase absoluta individualidade e não como simples ideia representativa de uma coleção de objetos semelhantes. Lembras-te, de certo, do exemplo clássico em psicologia: geralmente quando um homem comum percebe uma laranja não está percebendo "uma” laranja individualmente e, sim, apenas, a representação de toda a classe "laranja". O artista, o poeta, percebe e é especialmente capaz de expressar uma laranja, esta e não aquela. A aptidão, aliás, de apresentar o objeto de maneira inconfundível é uma das qualidades indispensáveis à boa arte. Para alcançar isto é necessário que o jovem artista desenvolva sua percepção nesse sentido individualizante ("omniexclusivo" para usar um neologismo baseado no teu), por oposição à visão totalizante, omninclusiva que notamos há pouco. $\mathrm{O}$ poeta, quando vê poeticamente a laranja, vê, ao mesmo tempo, uma laranja inconfundível e insubstituível, e uma laranja dentro, não só da classe da laranja, como também dentro de todo um universo objetivo, com todas as suas conotações aproximativas e antagônicas.

- Compreendo. Achas, contudo, que basta ao poeta desenvolver ao máximo essas duas capacidades de abordagem para chegar a perceber, de modo intenso e eficiente, o universo que o cerca? (FAUSTINO, 1964, pp. 42-43).

- Fizeste bem em lembrar esse aspecto que, se não é, deveria ser parte integrante, específica e necessária da percepção poética levada a um mínimo de relatividade. Uma percepção tendente ao absoluto tem de ser objetiva quanto possível, nesse sentido. Ocorre-me, todavia, uma outra feição, 
igualmente relevante da percepção do objeto por parte do poeta. Refiro-me ao fato de ver o poeta a coisa a um tempo de modo inteiramente original, fresco, recente - como se se tratasse de algo nunca visto ou nunca ouvido, ainda sem nome, recém-criado - e ao mesmo tempo carregada de toda a experiência não só pessoal, do próprio poeta, como de todos os homens. Uma percepção, em suma, a um tempo horizontal: a coisa no momento, agora, quase intemporal em toda a sua possível novidade considerada em abstrato; e vertical: a coisa e sua história, não só sua própria ancestralidade, como também a história do conhecimento que os homens - poetas ou não - têm tido dessa mesma coisa (FAUSTINO, 1964, pp. 45-46).

A integridade do poema-objeto que Faustino propõe não exige a total supressão do sujeito (o "tornar-se objetivo, imparcial, sem preconceitos"), como poderia fazer crer a citação que antecede essas últimas duas. Se ele deseja uma forma objetiva de expressão, deseja também a economia de recursos para a maior produtividade da linguagem. Sua objetividade não supõe aquilo que, na Poesia Concreta, tem a radicalidade trabalhada: a desaparição do eu lírico. Nos seus poemas, tanto quanto em suas propostas críticas, o sujeito poético está ali; mas a obra que avança deve ocultar e disfarçar o caminho da produção. A arte deve ser altamente consciente do nível crítico, autocrítico, lógico e abstrato do trabalho do criador-intelectual, mas apresentar-se como autônoma, não como comunicação de pensamentos/sentimentos do poeta. Nas palavras do autor,

[...] trata-se, de certo modo, daquela "simpatia" sem a qual não há verdadeiro conhecimento fora do campo das ciências exatas. Mas, ao mesmo tempo, os poetas devem procurar perceber, de modo mais direto e objetivo. Alguns poetas - nem todos maus - perdem, muita vez, por não se preocuparem com isso, a oportunidade de "apresentar" o objeto, em benefício de "comentários" sobre o mesmo, que só conseguem reduzir a exatidão e a intensidade da expressão poética. Como todos os defeitos de expressão, esse tem origem numa falha de percepção. A própria noção do todo é, frequentemente, vítima do mesmo perigo. Como o homem ordinário está sempre fazendo, alguns poetas - repito: nem sempre maus - percebem o todo de modo "apenas" fragmentado, deformado, exatamente porque se mostram incapazes de afastar, na medida do possível, e numa certa fase da percepção, suas próprias subjetividades, sua posição no interior de uma classe social, sem preconceitos filosóficos, estéticos etc., no momento de perceber o objeto - e mais ainda no momento de raciocinar sobre um objeto (FAUSTINO, 1964, p. 45).

Por fim, Faustino pondera uma questão cara a todos os teóricos e críticos de poesia, questão que ainda não havia sido considerada na sua abordagem às relações poeta-mundo e poesia-objetos: o ritmo. Para ele, o ritmo atua como elemento unificador do intrínseco com o extrínseco. De maneira heraclitiana, considera que todas as coisas fluem, têm ritmos, 
como o átomo e suas partes, e que o poeta deve saber identificar esses ritmos e encontrar a afinação ideal do poema com eles.

Também se pode acrescentar que o poeta, ao perceber um objeto, percebe, ao mesmo tempo, um certo sutil ritmo próprio de cada coisa, um ritmo que nasce do fato de todas as coisas estarem fluindo - como diria Heráclito - um ritmo interno e externo em estreita relação com o nome do objeto e com todos os fenômenos que nele se reúnem, um ritmo da coisa em si e da coisa em relação às outras coisas, pertencentes ou não à mesma categoria. Um ritmo semelhante ao que encontramos na observação do próprio átomo e de seus componentes, dos átomos dentro de uma molécula, de uma molécula dentro de um corpo, de um corpo no universo (FAUSTINO, 1964, p. 46).

O raciocínio simultaneamente global e específico, segundo o ritmo das coisas, exige certas qualidades do poeta. Para ver o todo, o poeta deve munir-se de alguns instrumentos: "uma certa medida de conhecimentos filosóficos, sociais e políticos, noções de estética geral, intimidade com a prosa e as demais artes, familiaridade cotidiana com os acontecimentos do mundo exterior, autoconhecimento, autocrítica, etc." (FAUSTINO, 1964, p. 50). Para ver o específico, faz-se necessário que o poeta

[...] saiba penetrar a realidade de cada coisa percebendo a um tempo sua estrutura, seu desenvolvimento e suas relações com as demais coisas, suas forças de transformação e de permanência, distinguindo em cada objeto o relevante do irrelevante (FAUSTINO, 1964, p. 50).

Para ver em projeção, por sua vez, é necessário perceber a mutabilidade das coisas, participando do sentimento trágico da vida:

[...] istoé, dando-se sempre conta do ritmo de transformação das situações atuais em situações futuras. Em suma, raciocinar sobre o mundo "evolutivamente": Por mais realista e empírico que um genuíno poeta seja, há sempre nele ou o profeta, o vidente, ou, pelo menos, o homem que procura carregar suas palavras de um elemento previsional, de tal ordem que elas possam provocar aquela impressão de eternidade inerente à verdadeira poesia (FAUSTINO, 1964, p. 50).

\section{CONSIDERAÇÕES FINAIS}

Os ensaios de Mário Faustino que abordamos neste trabalho, se não contaram com a assinatura do autor dentro de um projeto finalizado, pelo menos apresentam um percurso de pensamento sólido e complexo, radicado na formação e na experiência poéticas específicas do autor. As possíveis incongruências constatáveis nos ensaios certamente têm muito a ver com a dificuldade de construir teorias aliadas a sugestões 
metodológicas para conteúdos tão abrangentes quanto os que ele ativa na sua reflexão, que relaciona diversas instâncias categóricas - a da subjetividade criadora, a da objetividade das coisas em situação no mundo, a da percepção, a da linguagem etc.

É possível afirmar, com o conjunto dos textos, que Faustino estava interessado, mesmo quando defendia a vanguarda da Poesia Concreta, no passo adiante em relação a ela (na visão de Augusto e Haroldo de Campos, passo atrás): no livre uso do maquinário concreto dentro da instituição do verso, com vistas a propor soluções para o poeta futuro a partir de um maquinário poético renovado pelas ferramentas que estavam sendo propostas.

A respeito dos argumentos em prol de uma estética de objetos, por meio dos quais Faustino se mostra interessado em criar relações entre arte e coisas do mundo cotidiano, entre obra linguística e entes não linguísticos, pode-se dizer que ele queria projetar um processo semiótico complexo que vai da cisão entre aquilo que o objeto é (por exemplo, um sapato em um pé) e aquilo que ele representa ou pode representar (as camadas de significação, os signos e os marcadores; os valores abstratos da marca, por exemplo, ou a sua importância para um trabalhador ou contexto) até a sua recontextualização em texto/poema - quando se convocam, a critério do poeta, as camadas de signo, os marcadores linguísticos e o conjunto de relações que ele deseja ativar no poema. É graças àquela cisão inicial que a obra convocaria, do leitor, a participação do seu inconsciente, evento que faz com que a obra se torne capaz de exceder aquilo que diz e aquilo que faz. O real sedimentado na memória pode surgir associado à percepção dos objetos eles mesmos no mundo ou dos objetos em linguagem, se a expertise do poeta consegue produzir objetos tão condensados como os que Faustino deseja, e desde que com a imparcialidade que ele projeta. Podemos pensar exemplarmente suas formulações a partir da célebre frase de Antonin Artaud (1993, p. 72) em Van Gogh: um suicidado pela sociedade: "Não vejo um girassol sem recorrer aos girassóis de Van Gogh".

Essa linha de compreensão reverbera, ainda, aquela expressa na Origem da obra de arte, de Martin Heidegger: segundo o autor, a verdade do objeto manifesta-se (ele dirá, na verdade, que só se manifesta) exatamente na arte que opera o deslocamento de um objeto mundano. Essa arte, justamente por focalizar objetos da ordem das relações cotidianas automatizadas, permite que o objeto, em outra linguagem (ou seja, em outro ambiente semiótico), se apresente, como se pela primeira vez, a 
uma vista desarmada, a uma vista capaz de vê-lo em sua serventia, em sua realidade de objeto em situação - algo que, no mundo não literário, abstraímos em prol da produtividade irrefletida das coisas.

Faustino permitiu-se pensar que haveria um modo de dizer os objetos na poesia que poderia ser encarado como um veículo para dizer o mundo. Esse modo de dizer, na sua discussão, não é necessariamente o concreto-visual, o da transformação da palavra ela mesma em objeto, o da palavra mimetizando o modo de ser do objeto ou sendo o objeto de seu modo de significar. Por outro lado, em sua concepção, esse modo devia necessariamente ser consciente da concretude da linguagem e, portanto, se informar pelo concretismo. Ele entendia que o verso deveria ser superado, não para ser abandonado, mas para assumir-se na condição de objeto verbivocovisual de linguagem, coisa material, fora do domínio instrumental pré-determinado pelas formas fixas legadas pela tradição. Queria, enfim, tornar a linguagem visível e tangível, sem com isso fazer poema visual, tátil, tridimensional, verbivocovisual, já que a proposta concreta era de vanguarda e dificilmente constituiria um padrão do fazer futuro, no máximo uma informação estética entre outras. Como informação estética, discursiva ou não, Faustino alargava o conceito de poema-objeto para além do poema com teor concreto e alargava o poético para além do verso.

Esse é o resultado das iniciativas ensaísticas longas de Faustino. Se ele iria mais longe nessa linha, se mudaria os rumos dos seus argumentos para dar conta de outras demandas, nunca o saberemos. Sabemos, sim, que constituem uma das produções poéticas-críticas mais interessantes do debate literário brasileiro do século XX.

\section{$\overline{\text { REFERÊNCIAS }}$}

ARTAUD, Antonin. Van Gogh, o suicidado da sociedade. Rio de Janeiro: José Olímpio, 1993.

ASSIS BRASIL. Apresentação. In: FAUSTINO, Mário. Coletânea 2 - cinco ensaios sobre poesia. Org. Assis Brasil. Rio de Janeiro: Edições GRD, 1964, pp. 9-12.

ASSIS BRASIL. A nova literatura. Rio de Janeiro: Companhia Editora Americana, 1973.

CAMPOS, Augusto. Mário Faustino, o último Versemaker. In: Poesia, antipoesia, antropofagia E cia. São Paulo: Companhia das Letras, 2015.

CAMPOS, Haroldo de. A obra de arte aberta. In: CAMPOS, Augusto; CAMPOS, Haroldo; PIGNATARI, Décio. Teoria da poesia concreta. São Paulo: Brasiliense, 1981, pp. 36-39. 
CAMPOS, Haroldo de. Mário Faustino ou a impaciência órfica. In: Metalinguagem E outras metas. São Paulo: Perspectiva, 2006, pp. 189-212.

CAMPOS, Haroldo de. A ReOperação do texto. São Paulo: Perspectiva, $2013 a$.

CAMPOS, Haroldo de. Da transcriação: poética e semiótica da operação tradutora. In: Da transcriação. São Paulo: Perspectiva, 2013b, pp. 77-104.

FAUSTINO, Mário. Coletânea 2 - cinco ensaios sobre poesia. Org. Assis Brasil. Rio de Janeiro: Edições GRD, 1964.

FAUSTINO, Mário. Poesia-Experiência. São Paulo: Perspectiva, 1976.

FAUSTINO, Mário. Poesia completa / Poesia traduzida. São Paulo: Max Limonad, 1985.

FAUSTINO, Mário. O homem e sua hora e outros poemas. São Paulo: Companhia das Letras, 2002.

HEIDEGGER, Martin. A origem da obra de arte. Trad. Idalina Azevedo; Manuel António de Castro. São Paulo: Edições 70, 2010.

NUNES, Benedito. A poesia de meu amigo Mário. In: FAUSTINO, Mário. O homem e sua hora e outros poemas. São Paulo: Companhia das Letras, 2002, pp. 45-66.

NUNES, Benedito. O "fragmento" da juventude. In: BOSI, Alfredo (Org.). Leitura de poesia. São Paulo: Ática, 1996, pp. 175-19o.

POUND, Ezra. ABC da literatura. Trad. Augusto de Campos; José Paulo Paes. São Paulo: Cultrix, 2006.

VALÉRY, Paul. Poesia e pensamento abstrato. In: Variedades. Trad. Maiza Martins de Siqueira. São Paulo: Iluminuras, 2011, pp. 209-227.

Recebido: 2/7/2021

Aceito: 15/7/2021

Publicado: 30/12/2021 